\title{
31. A New Method of Ring Cleavage of Furan Compounds
}

By Masuo Murakami, Saburo SenoH, and Yoshiteru Hata

Institute of Scientific and Industrial Research, Osaka University

(Comm. by Y. Asahina, M.J.A., Feb. 13, 1956)

Two methods of synthesis of $\alpha$-ketocarboxylate by the oxidation of 2 -furoate have been reported, one patented ${ }^{1)}$ and the other by N. Clauson-Kass and F. Limborg. ${ }^{2)}$

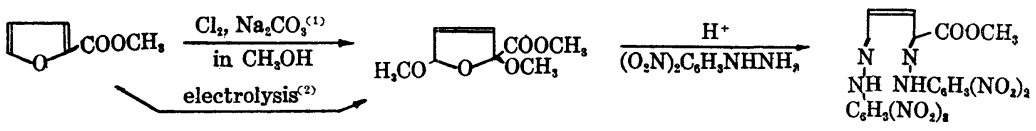

The present paper shows a new method of synthesis of $\alpha$-ketocarboxylates, third of this kind.

A suspension of difuroyl peroxide [I], which was prepared from 2-furoic acid according to the method described in the literature, ${ }^{3)}$ in absolute ethanol was treated with dry hydrogen chloride gas for a short period of time at room temperature under mechanical stirring. The reaction mixture gave ethyl 2 -furoate (m.p. $32-33^{\circ}$, ${ }^{4}$ quantitatively), and ethyl $\alpha, \delta$-dioxo- $\beta$-buten- $\alpha$-carboxylate bis- 2,4 dinitrophenylhydrazone [II] (m.p. 241-242 ${ }^{\circ}$ dec.; $\lambda_{\max }^{\text {mujol }}: 3.05 \mu, 3.17 \mu$ ( $>\mathrm{NH}) ; 5.88 \mu$ (conjugated ester)), and diethyl $\alpha$-ketoglutarate $z, 4$ dinitrophenylhydrazone [III] (m.p. $86-89^{\circ}$ ) by the treatment with 2,4-dinitrophenylhydrazine. This result suggests the occurrence of the ring cleavage of the furan compounds as described below.

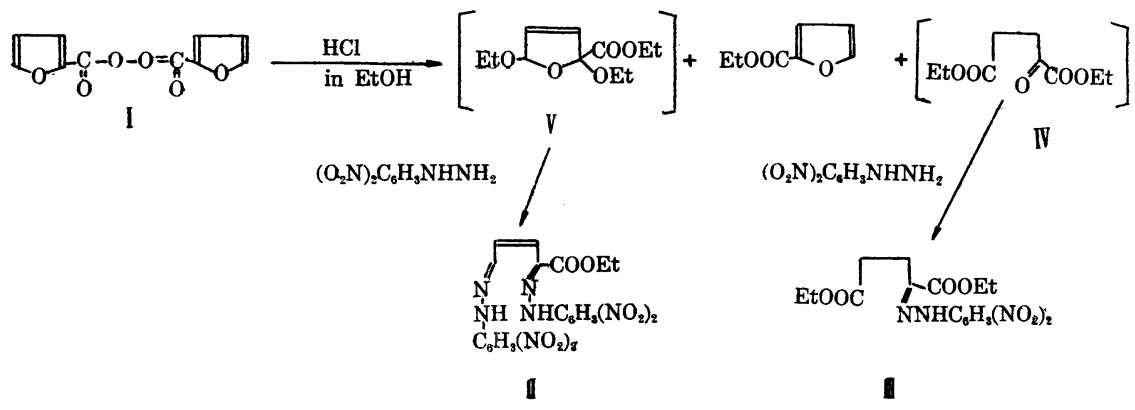

The structure of III was established by elementary analysis, by infrared absorption spectra $(3.12 \mu$ for $>\mathrm{NH}, 5.80 \mu$ for the ester, and $5.88 \mu$ for the conjugated ester), by converting it into $\alpha$-ketoglutaric acid 2,4-dinitrophenylhydrazone [IV] (m.p. $207-209^{\circ}$ dec. $)^{5)}$ by acid and alkaline hydrolysis, and also by mixed melting point determination of III or IV with the respective authentic samples 
prepared according to the method given in the literature. ${ }^{6)}$

It was also found that only II and no III are produced when the reaction mixture is neutralized with sodium bicarbonate, previous to the vacuum distillation; that yields of II decrease, whereas those of III increase as the time for the reaction to proceed at room temperature is prolonged; and that only III is found when the reaction mixture is heated for a short period of time. These results suggest that an intermediate, which gives bis-hydrazone [II], is converted into a substance, which would give mono-hydrazone [III], by hydrogen chloride.

In order to see whether or not 2,5-dialkoxy-2,5-dihydro-2-furoate [V] obtained by N. Clauson-Kaas ${ }^{2)}$ is the intermediate formed in the above reaction and also $\mathrm{V}$ can be converted into $\alpha$-ketoglutarate [VI] by hydrogen chloride, ethyl 2,5-diethoxy-2,5-dihydro-2-furoate [V] was synthesized from ethyl 2-furoate, according to the electrolytic oxidation method reported by N. Clauson-Kaas, in $55 \%$ of the theoretical yield. Physical constants for $\mathrm{V}$ were found to be as follows: b.p. $128-131^{\circ} / 11 \mathrm{~mm} ; n_{\mathrm{D}}^{22.8} 1.4384 ; d_{4}^{22.8} 1.0589 ; \mathrm{MR}_{\mathrm{D}}$ found 57.124; $\mathrm{MR}_{\mathrm{D}}$ calcd. 56.796; $\lambda \max 5.74 \mu$ (ester).

$\mathrm{V}$ was treated with ethanol saturated with dry hydrogen chloride gas and the reaction allowed to proceed either at room temperature for a long period of time or at boiling temperature for a short time. Diethyl $\alpha$-ketoglutarate [VI] was thus obtained in $51.4 \%$ of the theoretical yield. The infrared spectra (very strong band at $5.79 \mu$ for the ester) obtained from this compound agreed well with those taken for the authentic sample prepared according to the method given in the literature. ${ }^{6)}$

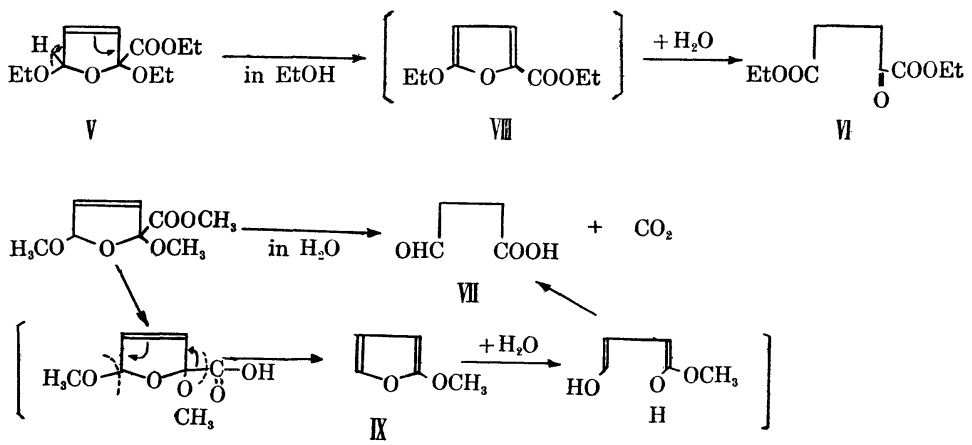

When aqueous hydrochloric or sulfuric acid was used in place of ethanolic hydrogen chloride, decarboxylation took place, giving $\beta$-formyl propionic acid [VII] in good yields. This compound was identified by preparing its 2, 4-dinitrophenylhydrazone (m.p. 199-200 dec. $)^{7)}$ and $p$-nitrophenylhydrazone (m.p. $176-177^{\circ}$ dec. $)^{8)}$ derivatives, 
and by taking mixed melting point with the respective derivatives prepared from the authentic sample.

The difference observed here may be that in the ethanol solution the furan ring undergoes cleavage so as to produce VIII as an intermediate, while in the aqueous solution IX is formed as an intermediate as a result of the hydrolysis of the carboxylate group followed by the decarboxylation in the acid solution.

The same treatment of difuroyl peroxide [I] gave VII accompanied by the evolution of carbon dioxide on heating the reaction mixture in the presence of water. These results indicate that $V$ is formed in the decomposition reaction of $\mathrm{I}$, and the mechanism may be interpreted as follows:

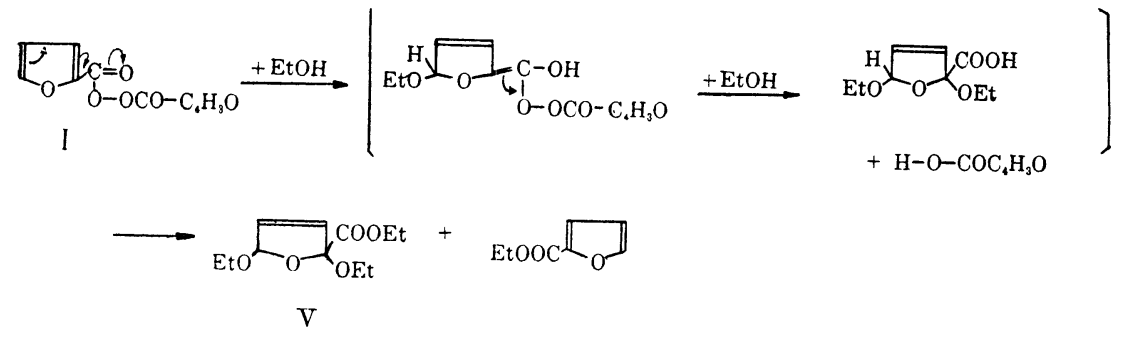

It is known that the reaction leading to the ring opening accompanied by decarboxylation requires the presence of a double bond in the furan ring. This was verified by the following results obtained: When methyl 2,5-dimethoxytetrahydro-2-furoate ${ }^{2)}$ was heated with a dilute solution of sulfuric acid no evolution of carbon dioxide took place and $\alpha, \delta$-dioxobutan- $\alpha$-calboxylic acid was obtained in good yields. This compound was identified by preparing its bis2, 4-dinitrophenylhydrazone (m.p. 205-206 ${ }^{\circ}$ dec.). The infrared spectra of this hydrazone had bands at $3.03 \mu, 3.16 \mu$ ( $>\mathrm{NH}), 4 \mu$ (broad, weak: associated $\mathrm{OH}$ of the carboxyl), $4 \mu+5.2 \mu$ (weak: $\equiv \stackrel{+}{\mathrm{N}}-\mathrm{H}$ ), $5.90 \mu$ (very weak: ?), and 6.2-6.33 $\mu$ (carboxylate ion and phenyl).

According to the patented method, ${ }^{1)}$ ethyl 2-furoate may give diethyl $\alpha$-ketoglutarate in a larger quantity than $V$, as may be seen from the fact that the mono-hydrazone [III] in a larger quantity than the bis-hydrazone [II] is isolated by the treatment of 2,4dinitrophenylhydrazine.

The mono-hydrazone [III] described above was obtained by the treatment of the reaction mixture with a solution of 2,4-dinitrophenylhydrazine in sulfuric acid-ethanol whereas ethyl methyl $\alpha$ ketoglutarate 2, 4-dinitrophenylhydrazone (m.p. 117-120 ${ }^{\circ}$ ) was obtained from the 2, 4-dinitrophenylhydrazine-sulfuric acid-methanol solution. The infrared spectra had bands at $3.15 \mu(>\mathrm{NH}), 5.77 \mu$ (ester), and $5.9 \mu$ (conjugated ester). 


\section{References}

1) British Patent No. 595,041 (1948) and No. 603,422 (1949). D. G. Jones and Imperial Chemical Industries Ltd.

2) N. Clauson-Kaas and F. Limborg: Acta Chem. Scand., 6, 551 (1952).

3) E. Baum: Ber., 37, 2951 (1904); N. A. Milas and A. McAleoy: J. Am. Chem. Soc., 56, 1219 (1934).

4) A. P. Dunlop and F. N. Peters: The Furans (Reinhold Publishing Corporation, New York, N. Y.), 513 (1953).

5) F. Knoop et al.: Z. physiol. Chem., 239, 30 (1936).

6) L. Friedman and E. Kosower: Organic Syntheses (John Wiley and Sons, Inc., New York, N. Y.), 26, 42 (1946); W. Wislisenus and M. Waldmüller: Ber., 44, 1564 (1911).

7) H. Kondo and H. Suzaki: Ber., 69B, 2459 (1936); C. S. Marvel et al.: J. Org. Chem., 16, 838 (1951); N. Clauson-Kaas and N. Elming: Acta Chem. Scand., 6, 560 (1952).

8) C. Harries: Ber., 45, 2585 (1912); I. A. D'yaknov and N. A. Lugovtsova: Zhur. Obscheĭ Khim (J. Gen. Chem.), 20, 2048 (1950); 21, 839 (1951); C. A., 45, 5632 (1951); 46, 440 (1952). 